7 - ORIGINAL ARTICLE

ISCHEMIA-REPERFUSION

\title{
Hyperbaric oxygen therapy and ischemia and reperfusion. A valuable association to attenuate ischemic lesion and hepatic reperfusion ${ }^{1}$
}

\author{
Daniele Moraes LosadaI, Maria Eliza Jordani de SouzaII, Maria Cecília Jordani" ${ }^{\text {II }}$ Maria Aparecida Neves Cardoso Picinato"I, \\ Clarice Fleury Fina ${ }^{\mathrm{II}}$, Omar Feres ${ }^{\mathrm{III}}$, Paulo Roberto Teixeira Michelone ${ }^{\mathrm{IV}}$, Orlando de Castro e Silva ${ }^{\mathrm{V}}$

\begin{abstract}
${ }^{\mathrm{I}}$ Graduate student, Marilia Faculty of Medicine (FAMEMA), Marilia-SP, Brazil. Main author. Conception, intellectual and scientific content of the study, designed the protocol, involved with technical procedures.

"Master, Unit of Liver Transplantation, Department of Surgery and Anatomy, FMRP-USP, Ribeirao Preto-SP, Brazil. Involved with technical procedures. IIIPhD, Department of Surgery and Anatomy, FMRP-USP, Ribeirao Preto-SP, Brazil. Critical revision.

${ }^{\text {IV }} \mathrm{PhD}$, Associate Professor, Surgery Department, FAMEMA, Marilia-SP, Brazil. Critical revision.

${ }^{\vee}$ Head, Department of Surgery and Anatomy, FMRP-USP, Ribeirao Preto-SP, Brazil. Conception and designed the protocol, intellectual and scientific content of the study.
\end{abstract}

\section{ABSTRACT}

PURPOSE: To investigate the consequences of the association between hyperbaric oxygen therapy and hepatic ischemia / reperfusion. METHODS: Wistar rats were divided into three groups: SHAM, rats submitted to surgical stress and anesthetic but not hepatic ischemia or reperfusion, I / R, rats submitted to total hepatic pedicle ischemia for $30 \mathrm{~min}$, followed by 5 min of reperfusion; HBO120, rats submitted to $120 \mathrm{~min}$ of hyperbaric oxygen therapy at two absolute atmospheres and immediately after submitted to the experimental protocol of ischemia and reperfusion. The preservation of the hepatic function was evaluated by determining mitochondrial swelling and malondialdehyde tissue level, as well as alanine aminotransferase and aspartate aminotranferase serum levels. The results were analyzed using the Mann-Whitney test and differences were considered significant for $\mathrm{p}<0.05$.

RESULTS: There were significant differences in values: mitochondrial swelling of the I / R group compared to SHAM and HBO120; malondialdehyde between SHAM vs. I / R, SHAM vs HBO120, and I / R vs HBO120, alanine aminotransferase between SHAM vs. I / R . There was no significant difference between groups in aspartate aminotransferase serum levels.

CONCLUSION: The association between hyperbaric oxygen therapy and hepatic ischemia and reperfusion process was positive. Key words: Hyperbaric Oxygenation. Ischemia. Reperfusion. Liver. Rats. 


\section{Introduction}

Although hyperbaric oxygen therapy is widely used in various contexts involving, especially, diseases related to phenomena of hypoxia, ischemia and reperfusion ${ }^{1,2}$ there is no scientific consensus on the subject; there are works in favor ${ }^{3,4}$ and unfavorable ${ }^{5}$ to this association. This phenomenon is due, at least in part, to a lack of studies that explore the biochemical basis of this association ${ }^{6,7}$, precisely the proposal of this work.

In order to determine whether exposure to hyperbaric oxygen therapy is harmful when applied before hepatic exposure to a process of ischemia and reperfusion, the analysis of mitochondrial swelling was adopted as a parameter of hepatic functional preservation because it is widely used in several literature works in this area ${ }^{8,9}$. Malondialdehyde tissue level (MDA) was taken as parameters of hepatic lesion for it is a recognized marker of lipid peroxidation ${ }^{10,11}$ as well as serum levels of alanine aminotransferase (ALT) and aspartate aminotransferase (AST) considered as indicators of hepatocellular integrity with an association between increased serum levels of these enzymes and acute hepatic damage ${ }^{12-15}$.

\section{Methods}

Twenty four male Wistar rats weighing between 200 to $300 \mathrm{~g}$ were divided into three groups: SHAM - mice submitted to surgical stress and anesthesia, without exposure to hyperbaric oxygen therapy (HBO) and without hepatic pedicle clamping, I / $\mathrm{R}$ - mice submitted to $30 \mathrm{~min}$ of liver ischemia by clamping the hepatic pedicle, followed by $5 \mathrm{~min}$ of reperfusion without $\mathrm{HBO}$ exposure; HBO120 - rats submitted to $120 \mathrm{~min}$ of $\mathrm{HBO}$ at two absolute atmospheres (ATA) and immediately underwent 30 min of ischemia followed by $5 \mathrm{~min}$ of reperfusion. The animals had free access to water and laboratory chow (Purina Nutrients Ltda.). The rats were kept inm the animal house of FMRP-USP at room temperature on 12-hour light-dark cycle according to the guidelines of the Ethics Committee for Animal Experimentation of FMRP-USP.

\section{Operation technique}

Surgical materials were clean and sterile. The animals were anesthetized with xylazine hydrochloride solution $(20 \mathrm{mg} /$ $\mathrm{ml})$ and ketamine hydrochloride $(50 \mathrm{mg} / \mathrm{ml})$ in a $1: 2$ ratio and applied $100 \mathrm{mg} / \mathrm{Kg}$. The anesthetic was applied in the right superficial gluteal muscle. The surgical procedure began with medial laparotomy which extended from the lower third of the xiphoid to the pubis. Next, exploration of the abdominal cavity, delicate dissection of the round ligament of the liver and identification of the hepatic pedicle was performed. Total hepatic pedicle clamping was carried out using a home-made clamp for 30 minutes. The rat was then subjected to 5 minutes of reperfusion. The animal sacrifice was performed through total exsanguination by puncturing the inferior vena cava.

\section{Hyperbaric oxygen therapy}

The application of HBO was performed in a collective chamber (simultaneous exposure to four rats) (Sechrist model 2500 B) directly pressurized with oxygen. Each session lasted $120 \mathrm{~min}$ : $15 \mathrm{~min}$ for compression and $15 \mathrm{~min}$ for decompression inside the chamber therefore, the animals underwent $90 \mathrm{~min}$ of continuous $\mathrm{HBO}$ at 2 ATA. HBO exposure was performed at the same period of the day.

\section{Mitochondrial swelling}

Transition of the inner mitochondrial membrane permeability was determined spectrophotometrically, at $540 \mathrm{~nm}$, by decreasing the optical density in medium containing $20 \mathrm{mM}$ calcium and phosphate $1 \mathrm{mM}^{16}$.

\section{Tissue and systemic injury}

Hepatic tissue injury was determined by measuring malondialdehyde levels in accordance with Ohkawa et al. ${ }^{17}$. The tissue and systemic injuries were determined through serum levels of the enzymes ALT, AST, respectively, through the kinetic method at $340 \mathrm{~nm}$, as described by Henry et al. ${ }^{18}$.

\section{Statistical analysis}

The results presented were statistically analyzed by nonparametric Mann-Whitney test with significance level set at $5 \%(\mathrm{p}<0.05)$. Statistical analyzes were performed with GraphPad Prisma 4.0 software (GraphPad Software Inc, Calif).

\section{Results}

Regarding the integrity preservation of the inner mitochondrial membrane, analyzed by mitochondrial swelling (Figure 1), a significant difference, $\mathrm{p}<0.05$ between the I / R group 
and the other groups (SHAM and HBO120).

Figura 1. Swelling mitocondrial

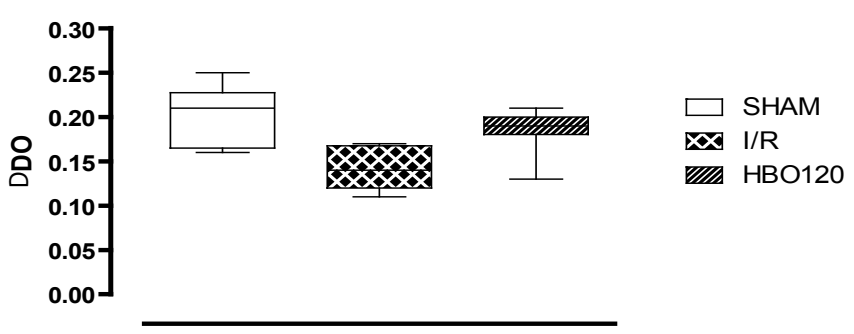

FIGURE 1 - Groups: SHAM (rats submitted to surgical stress without exposure to hyperbaric oxygen therapy - HBO - and without hepatic pedicle clamping, I / R (rats submitted to $30 \mathrm{~min}$ of ischemia followed by $5 \mathrm{~min}$ of reperfusion without $\mathrm{HBO}$ exposure) and $\mathrm{HBO} 120$ (rats submitted to 120 min of $\mathrm{HBO}$ at two absolute atmospheres and immediately underwent 30 min of ischemia followed by $5 \mathrm{~min}$ of reperfusion). $\mathrm{p}<0.05$ : SHAM vs I / $\mathrm{R}(\mathrm{p}<0.05), \mathrm{I} / \mathrm{R}$ vs HBO120 ( $<<0.05)$.

Malondialdehyde tissue levels showed a significant difference, $\mathrm{p}<0.05$, between groups: SHAM and I / R, SHAM and HBOI / R, I / R and HBOI / R (Figure 2).

Figura 2. MDA tecidual

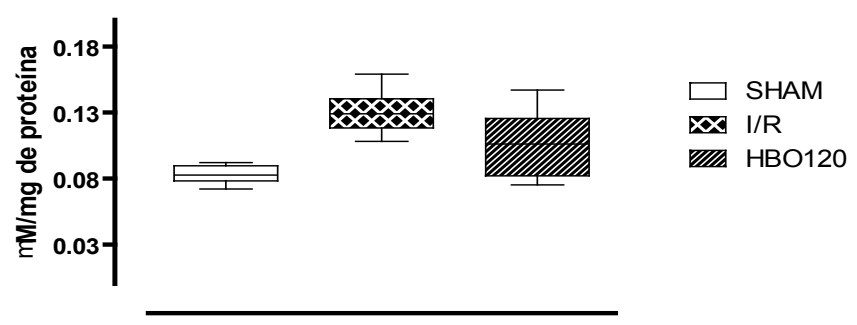

FIGURE 2 - Groups: SHAM (rats submitted to surgical stress without exposure to hyperbaric oxygen therapy - HBO - and without hepatic pedicle clamping), I / R (rats submitted to $30 \mathrm{~min}$ of ischemia followed by 5 min of reperfusion without $\mathrm{HBO}$ exposure) and HBO120 (rats submitted to $120 \mathrm{~min}$ of $\mathrm{HBO}$ at two absolute atmospheres and immediately after submitted to $30 \mathrm{~min}$ of ischemia followed by $5 \mathrm{~min}$ of reperfusion). $\mathrm{p}<0.05$ : SHAM vs I / R $(\mathrm{p}<0.05)$; SHAM vs HBO120 ( $<0.05)$, I / R vs HBO120 $(\mathrm{p}<0.05)$.

In relation to ALT serum levels there was significant difference $(\mathrm{p}<0.05)$ between I / R and SHAM group. AST serum levels showed no significant difference between the groups studied (Figure 3).

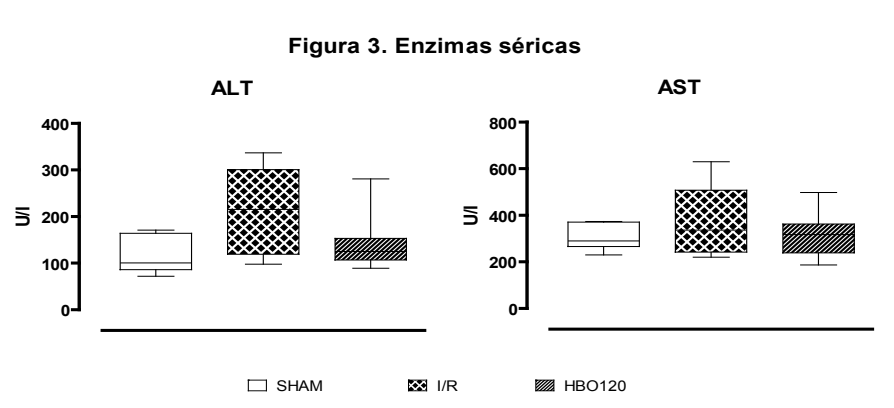

FIGURE 3 - Groups: SHAM (rats submitted to surgical stress without exposure to hyperbaric oxygen therapy - HBO - and without hepatic pedicle clamping), I / R (rats submitted to $30 \mathrm{~min}$ of ischemia followed by 5 min of reperfusion without $\mathrm{HBO}$ exposure) and HBO120 (rats submitted to $120 \mathrm{~min}$ of $\mathrm{HBO}$ at two absolute atmospheres and immediately after submitted to $30 \mathrm{~min}$ of ischemia followed by $5 \mathrm{~min}$ of reperfusion). Alanine aminotransferase (ALT), $\mathrm{p}<0.05$ : SHAM vs I / $\mathrm{R}(\mathrm{p}<0.05)$; SHAM vs HBO120 $(\mathrm{p}<0.05)$, I / R vs HBO120 ( $<0.05)$. Aspartate aminotransferase (AST): no significant difference between groups.

\section{Discussion}

Hepatic functional state can be characterized by determining the parameters of tissue mitochondrial permeability ${ }^{8,9}$ and the presence of malondialdehyde $(\mathrm{MDA})^{10,11}$, as well as systemic parameters such as ALT and AST enzymes serum levels ${ }^{5,13}$.

Mitochondrial swelling can be analyzed by the transition of the mitochondrial inner membrane permeability induced by $\mathrm{Ca}+2$ and phosphate. In this work, Figure 1 shows that I / R group had a smaller variation between the values of initial optical density and after calcium and phosphate induction. This suggests that the mitochondria of this group were already previously swollen by changes in mitochondrial inner membrane permeability probably by the action of reactive oxygen species, as evidenced by increased malondialdehyde tissue levels in this group. Studies in the literature show that oxidative stress induced by several factors, including ischemia / reperfusion causes rapid oxidation of the mitochondria antioxidant system (NADPH / GSH), which is accompanied by generation of reactive oxygen species, leading to a increased permeability transition of the inner mitochondrial membrane and consequently its depolarization ${ }^{19,20}$.

The association between hyperbaric oxygen and ischemia / reperfusion (group HBO120) showed similar behavior to SHAM group, suggesting that these mitochondria were not previously swollen, which was demonstrated by the induction of calcium and phosphate in these mitochondria. This result leads us to conclude that hyperbaric oxygen exerts a protective effect on the liver exposed to ischemia and reperfusion

Malondialdehyde (MDA), a metabolite of tissue lipid 
peroxidation, showed significantly higher values in I / R compared to the SHAM group, Figure 2. In HBO120 group, MDA values showed a significant difference compared to the SHAM group. However, a significant decrease in the tissue amount of this metabolite in HBO120 group compared to I / R group $(\mathrm{p}<0.05)^{20}$ was noted. It is suggested that the increase in MDA in the group undergoing oxygen therapy in relation to SHAM group may be due to exposure to hyperoxygenation, even with pre-conditioning effect. This pre-conditioning effect is due to the stimulus on the mitochondrial antioxidant system (NADPH / GSH), shown by the decrease levels compared to I / R group.

In relation to ALT serum levels, Figure 3, it was observed, in accordance to other studies in the literature ${ }^{12,13-21}$, an increase in I / R group in relation to SHAM group. It was noticed also that the association HBO and ischemia and reperfusion is positive in the preservation of hepatic cell integrity as it approximates the values of ALT to SHAM group.

In our study we observed no changes between the groups in relation to AST variable, Figure 3, as observed by other authors ${ }^{8}$. We attribute this discrepancy to variations in experimental protocol as well as different organic responses between animals exposed to the same ischemic / reperfusion stressor stimulus.

There are several studies that support the role of hyperbaric oxygen therapy in the promotion of increased tissue pressure of oxygen gas ${ }^{22-24}$ which would promote the preservation of tissue ATP reserves, thus reducing the ischemic injury during the injury process by ischemia and reperfusion. This reasoning justifies the benefit of hyperbaric oxygen therapy use in an ischemic process

However, considering that oxygen is the main biological precursor of oxidative stress, would a hyperoxia state not exacerbate the injury observed in a hepatic ischemia and reperfusion process? Based on these results, it is understood that the preservation of the inner mitochondrial membrane integrity, under hyperoxia conditions due to preconditioning effect, suggesting that stimulation of the antioxidant system of mitochondria, which protects the lipoperoxidation. This process, which is normally understood as being slow and gradual, in this study may have occurred quickly in order to protect hepatic tissue in adverse conditions. In this line, there is experimental work where the hyperbaric oxygen therapy is applied after tissue exposure to ischemia / reperfusion process ${ }^{25}$. Studies in this direction deserve to be developed in oxygen therapy with oxidants and antioxidants markers.

Basedontheseresults, itisunderstood thatnonexacerbation of tissue lesion is due to oxygen consumption proportional to cellular energetic metabolic demand for maintenance of homeostasis between formation / consumption of ATP reserves. In a surgical situation, theoretically, the ATP consumption corresponds to basal levels of cell function maintenance, and therefore on the availability of reagents for ATP formation the energy balance situation would not change. Over time and increased exposure to process of ischemia and concomitant depletion of reserves for ATP formation, an imbalance between formation / consumption of ATP would occur, triggering a biochemical cascade of ischemic / reperfusion lesion. Therefore, this study leads us to believe that the balance between these variables, in such protocol, is enough for the results shown.

More studies in this area are needed to better understand the mechanisms of action and therefore the side effects of the hyperbaric oxygen therapy and hepatic ischemia and reperfusion association.

\section{Conclusion}

The combination of hyperbaric oxygen therapy and hepatic ischemia and reperfusion is positive to promote improvement of the hepatic functional state without evidence of increased local or systemic injury.

\section{References}

1. Nylander G, Nordström H, LennartFranzén L, Henriksson KG, Larsson J. Effects of hyperbaric oxygen treatment in post-ischemic muscle: a quantitative morphological study. Scand J Plast Reconstr Surg Hand Surg. 1988;22(1):31-9.

2. Chen MF, Chen HM, Ueng SW, Shyr MH. Hyperbaric oxygen pretreatment attenuates hepatic reperfusion injury. Liver. 1998;18(2):110-6.

3. Castro-Silva O, Sankarankutty AK, Martinelli AL, Souza FF, Teixeira AC, Feres O, Mente ED, Oliveira GR, Akita R, Muglia V, Elias J Jr, Ramalho LN, Zucoloto S. Therapeutic effect of hyperbaric oxygen in hepatic artery thrombosis and functional cholestasis after orthotopic liver transplantation.Transplant Proc. 2006;38(6):1913-7.

4. Kihara K, Ueno S, Sakoda M, Aikou T. Effects of hyperbaric oxygen exposure on experimental hepatic ischemia reperfusion injury: relationship between its timing and neutrophil sequestration. Liver Transplant. 2005(12);11:1574-80.

5. Lima CX, Sanches MD, Rezende Neto JB, Oliveira e Silva RC, Teixeira MM, Souza D da G, Santos Gde C, Melo JR. Hyperbaric oxygen therapy aggravates liver reperfusion injury in rats. Acta Cir Bras. 2008;23(4):315-21.

6. Castro-Silva O, Centurion S, Pacheco EG, Brisotti JL, Oliveira AF, Sasso KD. Aspectos básicos da lesão de isquemia e reperfusão e do pré-condicionamento isquêmico. Acta Cir Bras. 2002;17:96-100.

7. Zamboni WA, Roth AC, Russell RC, Graham B, Suchy H, Kucan JO. Morphologic analysis of the microcirculation during reperfusion of ischemic skeletal muscle and the effect of hyperbaric oxygen. Plast Reconstr Surg. 1993;91(6):1110-23.

8. Castro-Silva O, Sankarankutty AK, Correa RB, Ferreira J, Vollet 
Filho JD, Kurachi C, Bagnato VS. Autofluorescence spectroscopy in liver transplantation: preliminary results from a pilot clinical study. Transplant Proc. 2008;40(3):722-5.

9. Tolentino EC, Castro-Silva O, Zucoloto S, Souza ME, Gomes MC, Sankarankutty AK, Oliveira GR, Feres O. Effect of hyperbaric oxygen on liver regeneration in a rat model. Transplant Proc. 2006;38(6):1947-52.

10. Miranda LEC, Viaro F, Ceneviva R, Évora PRB. As bases experimentais da lesão por isquemia e reperfusão do fígado: revisão. Acta Cir Bras. 2004;19(1):3-12.

11. Kurir TT, Markotic A, Katalinic V, Bozanic D, Cikes V, Zemunik T, Modun D, Rincic J, Boraska V, Bota B, Salamunic I, Radic S. Effect of hyperbaric oxygenation on the regeneration of the liver after partial hepatectomy in rats. Braz J Med Biol Res. 2004;37(8):12317.

12. Ramachandran S, Liaw JM, Jia J, Glasgow SC, Liu W, Csontos K, Upadhya GA, Mohanakumar T, Chapman WC. Ischemiareperfusion injury in rat steatotic liver is dependent on NFkB P65 activation. Transplant Immunol. 2012;26(4):201-6.

13. Kanoria S, Glantzounis G, Quaglia A, Dinesh S, Fusai G, Davidson BR, Seifalian AM. Remote preconditioning improves hepatic oxygenation after ischaemia reperfusion injury. Transplant Int. 2012;25(7):783-91.

14. Idetsu A, Suehiro T, Okada K, Shimura T, Kuwano H. Hyperbaric oxygenation promotes regeneration of biliary cells and improves cholestasis in rats. World J Gastroenterol. 2011;17(17):2229-35.

15. Giannini EG, Testa R, Savarino V. Liver enzyme alteration: a guide for clinicians. CMAJ. 2005;172(3):367-79.

16. Jordani MC, Santos AC, Prado INR, Uyemura AS, Curti C. Flufenamic acid as an inducer of mitochondrial permeability transition. Mol Cell Biochem. 2000;210(1-2):153-8.

17. Ohkawa H, Ohishi N, Yagi K. Assay for lipid peroxides in animal tissues by thiobarbituric acid reaction. Anal Biochem. 1979;95(2):351-8.

18. Henry JR, Chiamori N, Golub OJ, Berkman S. Revised espectrophotometric methods for the determination of glutamicoxalacetic transaminase, glutamic - piruvic transaminase and latic acid dehydrogenase. Am J Clin Pathol. 1960;34:381-98.

19. Niemiinen AL, Byrne AM, Herman B, Lemasters JJ. Mitochondrial permeability transition in hepatocytes induced by t-BuOOH: NAD(P) H and reative oxigen species. Am J Physol. 1997;272(4):C1286-C94.

20. Barbosa Jr. AB, Jordani MC, Souza MEJ, Franco CFF, Picinato MAN, Castro e Silva Jr O. Avaliação do intumescimento osmótico mitocondrial do fígado submetido a isquemia parcial e ao précondicionamento isquêmico. Acta Cir Bras. 2000;15(Supl 2):63-4.

21. Centurion SA, Centurion LM, Souza ME, Gomes MC, Sankarankutty AK, Mente ED, Castro e Silva O. Effects of ischemic liver preconditioning on hepatic ischemia/reperfusion injury in the rat. Transplant Proc. 2007;39(2):361-4.

22. Thom SR. Hyperbaric oxygen therapy. J Intensive Care Med. 1989;4:58-74.

23. Thom SR. Hyperbaric oxygen: its mechanisms and efficacy. Plast Reconstr Surg. 2011;127(Suppl 1):131S-41S.

24. Jung S, Wermker K, Poetschik H, Ziebura T, Kleinheinz J. The impact of hyperbaric oxygen therapy on serological values of vascular endothelial growth factor (VEGF) and basic fibroblast growth factor (bFGF). Head Face Med. 2010;6:29.

25. Özden TA, Uzun H, Bohloli M, Toklu AS, Paksoy M, Simsek $\mathrm{G}$, Durak H, Issever H, Ipek T. The effects of hyperbaric oxygen treatment on oxidant and antioxidants levels during liver regeneration in rats. Tohoku J Exp Med. 2004;203(4):253-65.

\section{Acknowledgements}

To Hermes Murta and José Carlos Vanni (Technicians at Surgical Technique and Experimental Surgery of Department of Surgery and Anatomy, FMRP-USP) for assisting in the methodological design of this study.

\section{Correspondence:}

Orlando de Castro e Silva

Hospital das Clínicas de Ribeirão Preto

Departamento de Cirurgia e Anatomia

Avenida Bandeirantes, 3900/9 ${ }^{\circ}$ andar

14048-900 Ribeirão Preto - SP Brasil

orlando@fmrp.usp.br

Received: September 18, 2012

Review: November 19, 2012

Accepted: December 20, 2012

Conflict of interest: none.

Financial source: Sao Paulo Research Foundation (FAPESP)

${ }^{1}$ Research performed at Unit of Liver Transplantation, Department of Surgery and Anatomy, Ribeirao Preto School of Medicine, University of Sao Paulo (FMRP-USP), Brazil. 